\title{
Association of urban forest landscape characteristics with biomass and soil carbon stocks in Harbin City, Northeastern China
}

\author{
Hailiang Lv ${ }^{1,2}$ ， Wenjie Wang ${ }^{\text {Corresp., }}{ }^{1,2}{ }^{2}$, Xingyuan He ${ }^{1}$, Chenhui Wei ${ }^{1}$ ， Lu Xiao ${ }^{1}$ ， Bo Zhang ${ }^{2}$, Wei Zhou ${ }^{2}$ \\ 1 Northeast Institute of Geography and Agricultural Ecology, Chinese Academy of Sciences, Changchun, The People's Republic of China \\ 2 Northeast Forestry University, Harbin, The People's Republic of China \\ Corresponding Author: Wenjie Wang \\ Email address: wangwenjie@iga.ac.cn
}

Background . Urban forests help in mitigating carbon emissions; however, their associations with landscape patterns are unclear. Understanding the associations would help us to evaluate urban forest ecological services and favor urban forest management via landscape regulations. We used Harbin, capital city of the northernmost province in China, as an example and hypothesized that the urban forests had different landscape metrics among different forest types, administrative districts, and urban-rural gradients, and these differences were closely associated with forest carbon sequestration in the biomass and soils.

Methods. We extracted the urban forest tree coverage area on the basis of 2 GF-1 remote sensing images and object-oriented based classification method. The analysis of forest landscape patterns and estimation of carbon storage were based on tree coverage data and 199 plots. We also examined the relationships between forest landscape metrics and carbon storage on the basis of forest types, administrative districts, ring roads, and history of urban settlements by using statistical methods.

Results. The small patches covering an area of less than 0.5 ha accounted for $72.6 \%$ of all patches (average patch size, $0.31 \mathrm{ha}$ ). The mean patch size (AREA_MN) and largest patch index (LPI) were the highest in the landscape and relaxation forest and Songbei District. The landscape shape index (LSI) and number of patches linearly decreased along rural-urban gradients $(p<0.05)$. The tree biomass carbon storage varied from less than 10 thousand tons in the urban center (first ring road region and 100-year regions) to more than 100 thousand tons in the rural regions (fourth ring road and newly urbanized regions). In the same urban-rural gradients, soil carbon storage varied from less than 5 thousand tons in the urban centers to 73-103 thousand tons in the rural regions. The association analysis indicated that the total forest area was the key factor that regulates total carbon storage in trees and soils. However, in the case of carbon density (ton ha-1), AREA_MN was strongly associated with tree biomass carbon, and soil carbon density was negatively related to LSI $(p<0.01)$ and AREA_MN $(p<0.05)$, but positively related to LPI $(p<0.05)$.

Discussion. The urban forests were more fragmented in Harbin than in other provincial cities in Northeastern China, as shown by the smaller patch size, more complex patch shape, and larger patch density. The decrease in LSI along the rural-urban gradients may contribute to the forest carbon sequestrations in downtown regions, particularly underground soil carbon accumulation, and the increasing patch size may benefit tree carbon sequestration. Our findings help us to understand how forest landscape metrics are associated with carbon storage function. These findings related to urban forest design may maximize forest carbon sequestration services and facilitate in precisely estimating 
the forest carbon sink. 
1

2 Association of urban forest landscape characteristics with biomass and soil carbon stocks in 3

4

5 Hailiang Lv ${ }^{1,2}$, Wenjie Wang ${ }^{1,2}$, Xingyuan He ${ }^{1}$, Chenhui Wei ${ }^{1}$, Lu Xiao $^{1}$, Bo Zhang ${ }^{2}$, Wei 6 Zhou $^{2}$

$7{ }^{1}$ Northeast Institute of Geography and Agricultural Ecology, Chinese Academy of Sciences, 8 Changchun 130102, Jilin, China;

$9 \quad 2$ Northeast Forestry University, No. 26 Hexing Road, Harbin 10040, China

10 Corresponding author:

11 Wenjie wang

12 Email address: wjwang225@hotmail.com 


\begin{abstract}
Background. Urban forests help in mitigating carbon emissions; however, their associations with landscape patterns are unclear. Understanding the associations would help us to evaluate urban forest ecological services and favor urban forest management via landscape regulations. We used Harbin, capital city of the northernmost province in China, as an example and hypothesized that the urban forests had different landscape metrics among different forest types, administrative districts, and urban-rural gradients, and these differences were closely associated with forest carbon sequestration in the biomass and soils.
\end{abstract}

Methods. We extracted the urban forest tree coverage area on the basis of 2 GF-1 remote sensing images and object-oriented based classification method. The analysis of forest landscape patterns and estimation of carbon storage were based on tree coverage data and 199 plots. We also examined the relationships between forest landscape metrics and carbon storage on the basis of forest types, administrative districts, ring roads, and history of urban settlements by using statistical methods.

Results. The small patches covering an area of less than 0.5 ha accounted for $72.6 \%$ of all patches (average patch size, $0.31 \mathrm{ha}$ ). The mean patch size (AREA_MN) and largest patch index (LPI) were the highest in the landscape and relaxation forest and Songbei District. The landscape shape index (LSI) and number of patches linearly decreased along rural-urban gradients $(p<0.05)$. The tree biomass carbon storage varied from less than 10 thousand tons in the urban center (first ring road region and 100-year regions) to more than 100 thousand tons in the rural regions (fourth ring road and newly urbanized regions). In the same urban-rural gradients, soil carbon storage varied from less than 5 thousand tons in the urban centers to 73-103 thousand tons in the rural regions. The association analysis indicated that the total forest area was the key factor that regulates total carbon storage in trees and soils. However, in the case of carbon density (ton ha ${ }^{-1}$ ), AREA_MN was strongly associated with tree biomass carbon, and soil carbon density was negatively related to LSI $(p<0.01)$ and AREA_MN $(p<0.05)$, but positively related to LPI $(p<0.05)$.

Discussion. The urban forests were more fragmented in Harbin than in other provincial cities in Northeastern China, as shown by the smaller patch size, more complex patch shape, and larger patch density. The decrease in LSI along the rural-urban gradients may contribute to the forest carbon sequestrations in downtown regions, particularly underground soil carbon accumulation, and the increasing patch size may benefit tree carbon sequestration. Our findings help us to understand how forest landscape metrics are associated with carbon storage function. These findings related to urban forest design may maximize forest carbon sequestration services and facilitate in precisely estimating the forest carbon sink. 


\section{Introduction}

The value of urban forests in mitigating carbon emissions has received considerable interest among scientists and urban planners (Zhao et al., 2010; Setala et al., 2013) because of accelerated urbanization and ecological and environmental problems worldwide (Maruotti, 2008; Mccarthy et al., 2010; Zhao et al., 2015; Zhao \& Wentz, 2016). The carbon sink function of urban forests in many cities such as Miami-Dade and Gainesville, USA (Escobedo et al., 2010); Hangzhou, China (Zhao et al., 2010); and Chuncheon, Kangleung, and Seoul, Middle Korea (Jo, 2002) have been assessed for offsetting regional carbon emissions. Even though researchers worldwide have estimated the storage and sequestration of carbon in urban forests (Liu \& Li, 2012; Nowak et al., 2013, Zhang et al., 2015), less attention has been paid to the relationship between the landscape pattern and carbon storage functions in urban forests (Ren et al. 2013). In general, urban regions have limited space for urban forests, and the landscape patterns of urban forests could strongly modify forest ecological services, such as species diversity conservation (Zhang et al., 2017b) and cooling island effects (Ren et al., 2013). To date, associations between carbon sinks and landscape patterns have not been well-defined, and untangling the associations is essential to precisely evaluate ecological services of urban forests (Ren et al., 2013; Zhang et al., 2017b; Ren et al., 2018; Wang et al., 2018).

Quantification of forest landscape metrics is useful for understanding the structure and configuration of the urban forest landscape (Uuemaa et al., 2013). Possible indices include arearelated parameters, such as the total area for green infrastructure (TA), number of forest patches (NP), and mean patch size (AREA_MN); forest shape features, such as perimeters of patch and perimeter-area ratio (PARA); patch aggregation features, such as landscape shape index (LSI), largest patch index (LPI), and distance between patches (Liu et al., 2009; Gounaridis et al., 2014). These indices yield a lot of information and can be quantified easily by using ArcGIS and Fragstats software; they have been used as indicators in many studies on land use changes, habitat alterations, and landscape regulating functions under both urban and natural conditions (Uuemaa et al., 2013; Ren et al., 2013; Zhang et al., 2017b). Associations between urbanization intensity 
76

77

78

79

80

81

(urban-rural gradients) and ecological services, such as carbon storage capacity, have been used to understand urbanization and green infrastructure service interactions (Zhan et al., 2015; Lv et al., 2016) without considering forest landscape patterns. Clarification of the relationships between urban forest landscape characteristics and carbon storage may be helpful in understanding how urbanization affects carbon storage in trees and soils and finding possible indicators for evaluations of urban forest carbon sink functions; the possible parameters include urbanization intensity, landscape metrics, and tree size and forest community attributes, etc. (Wang et al., 2005; Wang et al., 2011; Zhang et al., 2017b).

Currently, China is in a period of rapid urbanization, and there is a general hope for good environmental security from urban green vegetation, such as forests (Mu et al., 2004; Wang, 2009; Liang et al., 2014; He et al., 2017; Zheng et al., 2017; Wang et al., 2018). In China, the urban forests can easily be classified into different types on the basis of their location and functions, such as roadside forest distributed on both sides of roads; affiliation forest in different units of universities, schools, and institutes; landscape and relaxation forest in gardens and parks; and ecological public welfare forest for the prevention of soil erosion, floods, etc. (He et al., 2004). The division of different administrative districts in the same city facilitates possible management by public and private units (Liu et al., 2007), including urban vegetation. Moreover, ring-road development and the history of urban settlements indicating urban-rural gradients are typical ways for understanding the urbanization effects (Xiao et al., 2016a). Studies that combine forest types, administrative districts, and urban-rural gradients, together with suitable landscape metrics, may favor the quantification of urban forest landscape features and their associations with forest ecological processes (Liu et al., 2009; Ren et al., 2013) and provide possible strategies for forest city design during the fast urbanization process in China (Zhang et al., 2017b).

Harbin, a typical provincial capital city in Northeastern China, has been checked for urbanization effects on urban tree species diversity and possible associations with bird species alternations (Xiao et al., 2016a), tree species configuration problems in urban afforestation (Xiao et al., 2016b), and best tree species for improving urban forest soils (Lu et al., 2016; Wang et al., 
103

104

105

106

107

108

109

110

111

112

113

114

115

116

117

118

119

120

121

122

123

124

125

126

127

128

2017) and soil glomalin and mycorrhizal features (Zhong et al., 2016; Cui \& Mu, 2016). However, whole carbon storage at city scale, especially soil organic carbon (SOC), and the relationships with landscape pattern characteristics are still unknown (Ying et al., 2009; Lv et al., 2016).

In this paper, we used Harbin, the northernmost province capital city in China, as an example and hypothesized that urban forests have largely different landscape metrics on the basis of the forest type, administrative district, and urban-rural gradients, and these differences are closely associated with forest carbon sequestration in the biomass and soils. The following questions have been answered in this paper: (1) How large are the variations in the characteristics of urban forest landscapes in Harbin City? What are the differences in forest types, administrative districts, and urban-rural gradients? (2) How large are the differences in urban forest biomass and underground soils? Which landscape metrics are most significantly associated with these carbon sequestration differences? (3) Is there any management suggestions from the view of landscape configurations for promoting carbon storage in urban forests? What type of landscape-related suggestions for the exact evaluation of urban forest carbon storage could be derived? The solutions will favor landscape-carbon sequestration sciences and help to define a suitable strategy for urban afforestation and management.

\section{Materials \& Methods}

\section{Study area}

The study area is located in the urban area of Harbin City $\left(45^{\circ} 45^{\prime} \mathrm{N}, 126^{\circ} 38^{\prime} \mathrm{E}\right.$; Figure 1$)$, the capital of Heilongjiang Province in Northeastern China. The average elevation of Harbin City is $151 \mathrm{~m}$ above sea level. The municipal district covers an area of 10,198 $\mathrm{km}^{2}$. The total area within the fourth ring road is about $600 \mathrm{~km}^{2}$, and the built-up area within the fourth ring road is 345.3 $\mathrm{km}^{2}$. Until 2014, 4.7 million people lived in the downtown area, according to the Statistical Yearbook of Harbin (http://www.harbin.gov.cn/col/col39/index.html). The mean temperatures in January and July are $-17.6^{\circ} \mathrm{C}\left(0.3^{\circ} \mathrm{F}\right)$ and $23.1{ }^{\circ} \mathrm{C}\left(73.6^{\circ} \mathrm{F}\right)$, according to the climate data from 1981 to 2010 (http://data.cma.cn/site/index.html). The annual precipitation is $524 \mathrm{~mm}$ (20.6 in). 
129 The frost-free period lasts 140 days, while the ice period lasts 190 days (Zhang et al., 2011). The 130 most prevalent soil across Harbin is the black soil (Luvic Phaeozem, FAO) (Chang, 2015).

131 The main region in Harbin City is composed of 5 administrative districts. The main forest 132 types are roadside forest $(\mathrm{RF})$, ecological public welfare forest $(\mathrm{EF})$, landscape and relaxation 133 forest (LF), and affiliated forest (AF), according their location, ecological function, and

134

135

136

137

138

139

140

141

142

143

144

145

146

147

148

149

150

151

152

153

154

155

management objectives (He et al., 2004). Long-term records (up to 1900s) on the urbanization process in Harbin are available. The urban land in Harbin was only $12 \mathrm{~km}^{2}$ in 1907, and it had increased ca. 30-fold to $333 \mathrm{~km}^{2}$ in 2014 (Fig. 1). The urban population in Harbin increased 18fold from 0.54 million in 1946 to 9.87 million in 2014 (Yi et al., 2006). The expansion of ring roads is also a good substitute for urban-rural gradients in Harbin (Huang et al., 2010). These features made Harbin City a good example for the study of urbanization effects on urban forest landscape characteristics and their associations with carbon storage capacity.

\section{Image processing and tree coverage interpretation}

Two multispectral GF-1 images with a resolution of $2 \mathrm{~m} \times 2 \mathrm{~m}$ (China Center for Resources Satellite Data and Application; CRESDA) acquired on September 26, 2014, were used for the forest coverage extraction. Image preprocessing procedures included radiometric correction, FLAASH atmospheric correction, ortho-rectification, and image fusion and clipping. We extracted the urban forest coverage by using the object-oriented based classification method, according to texture information, spectral information, and spatial attributes of remote sensing images. The attribute assignment and manual modifications were performed with ArcGIS map (ESRI, version 10.0).

We used per pixel (Wentz \& Zhao, 2015) and object-based (Li et al., 2015) validation methods to evaluate the accuracy of urban forest tree coverage extraction. Per pixel methods are used to check whether an individual pixel is classified correctly (Wentz \& Zhao, 2015). The overall accuracy of the tree coverage extraction was $97.67 \%$, with a miss factor of 0.06 and detection rate and quality percentage of $94.21 \%$. Object-based accuracy assessment was performed using manually digitalized results from Google Earth satellite images (resolution, $0.59 \mathrm{~m}$ ) as reference 
156

157

158

159

160

161

162

163

164

165

166

167

168

169

170

171

172

173

174

175

176

177

178

179

180

181

data (Li et al., 2015). We randomly selected 100 plots $(500 \mathrm{~m} \times 500 \mathrm{~m})$ to compare the discrepancies between the classified results and reference maps. Figure 2 shows the scatter plot of tree coverage between classification results and corresponding reference data (Google Earth image). It is evident that these scattered points are distributed near the $45^{\circ}$ line and $\mathrm{R}^{2}$ is more than 0.99. The results for forest tree coverage in Harbin City are presented in Figure 3.

\section{Analysis of landscape metrics}

The analysis of forest landscape characteristics was based on 4 forest types (He et al., 2004), 5 administrative districts, 4 ring roads, and 7 periods of urban settlements (Chen et al., 2005; Zhang et al., 2015) and performed using Fragstats (v4.2.589; Fig. 3). The landscape metrics were selected according to their ecological meanings and referenced from Liu et al. (2009) and Gao \& Yu (2014). Seven indices (Appendix Table 1 in supplemetall files) were finally selected. The area and edge indices were total area (TA), number of patches (NP), largest patch index (LPI), and mean patch area (AREA_MN); shape index was area-weighted perimeter-area ratio (PARA_AM); and aggregation indices were landscape shape index (LSI) and mean Euclidean nearest-neighbor distance (ENN_MN).

The relationships between patch perimeter and patch area are the bases for most shape indices, and the Euclidean nearest-neighbor distance $(\mathrm{ENN})$ is the simplest measure of patch context. We also analyzed the frequency distribution of 4 indices at patch level, namely, patch area, patch perimeter, perimeter-area ratio (PARA), and ENN. The spatial scale for analysis was $2 \mathrm{~m}$, the same as the GF-1 image resolution, and the 8-neighbor patch rule was used.

\section{Field study and estimation of carbon storage}

The field study was conducted between August and September 2014. During the field study, we recorded the location of each plot (by using GPS), tree species composition, diameter at breast height (DBH; $1.3 \mathrm{~m})$, basal area $(1.3 \mathrm{~m}$, at breast height), and height (measured using a Laster tree height meter, Nikon forestry PRO550 Nikon, Japan) of trees with a diameter greater than $1 \mathrm{~cm}$. The soil samples $(0-20 \mathrm{~cm})$ were collected at the same time by using a $100 \mathrm{~cm}^{3}$ cutting ring (4 
182

183

cutting rings per plot; M\&Y Instrument Technology Co. Ltd., Shanghai, China). A fixed volume of intact soil $\left(400 \mathrm{~cm}^{3}\right)$ was stored in a cloth soil bag and air-dried in a dry ventilated room to constant weight for laboratory analysis.

The sampling plots were allocated according to forest coverage in different forest types, administrative districts, ring roads, and history of urban settlements (Fig. 1). Plot allocation is listed in Table 1. The estimation of total carbon storage was the random sampling statistics of carbon storage density (carbon stocks per tree cover) of different forest types, ring roads, administrative districts, and history of urban settlements (Lv et al., 2016) and their tree coverage area shown in Figure 3.

$$
\text { Carbon }_{\text {storage }}=\sum_{i=1}^{j} C D_{i} \times T C_{i} \text { (1) }
$$

where $C D_{i}$ is the ith carbon storage density of different forest types, ring roads, administrative districts, and history of urban settlements, and $T C_{i}$ is the $i t h$ urban forest tree coverage area of these urban forest classifications.

The dryweight biomass of the trees was estimated using tree biomass allometric growth equations obtained from published literature and root-to-shoot ratio of 0.26 when below-ground biomass equations were absent (Appendix Table 2 in supplemental files). Total tree dryweight biomass was converted to total stored carbon by multiplying by 0.5 . The biomass carbon storage density $\left(\mathrm{kg} \mathrm{C} \cdot \mathrm{m}^{-2}\right)$ was estimated using total tree biomass carbon in each plot, divided by the plot area.

The SOC content was determined using the heated dichromate/titration method (Bao, 2000; Wang et al., 2011). SOC density in each plot was the product of SOC content, soil bulk density, and sampling soil depth $(20 \mathrm{~cm}$ in this study).

\section{Statistical analysis}

The landscape patterns of the urban forests were characterized by the frequency distribution of different metrics of pooled whole-city data. For finding the changes at urban-rural gradients in ring road development and history of urban build-up, linear regression was used for detecting steady changes during urbanization processes. 
Pearson's correlation, linear and stepwise regression analyses, smoothing analysis, and

210

211

212

213

214

215

216

217

218

219

220

221

222

223

224

225

226

227

228

229

230

231

232

233

234

235

bivariate normal distribution were performed using SPSS (version 19.0, 2010, IBM, USA) and JMP (SAS, version 10, USA), respectively, to understand the associations between landscape characteristics and carbon stocks. All tables and figures 2, 4, 5 were created with MS Excel 2010 (14.0.4760.1000, Microsoft, Redmond, WA, USA); figures 1 and 3 depicted using ArcGIS 10.0; figure 6 depicted using JMP 10.0.

\section{Results}

\section{Spatial distribution and patch characteristics of urban forests}

The spatial distribution of urban forests in Harbin was highly uneven (Fig. 3). The large patches mainly belonged to LF, and RF was mainly a long rectangular strip. AF was mainly aggregated in the central urban regions, whereas EF was mainly located in the outer rural region of Harbin City (Figs. 1 and 3). With respect to urban-rural gradients, large patches were mainly distributed in the third ring road region, forest patches in the second ring road region were mainly aggregated in the south area, and north regions of the second ring road had little forest cover. The urban forest in the oldest central urban regions was mainly AF. The urban forests in the newest urbanized regions, such as the north side of Songhua River, were mainly EF. In different administrative districts, most patches in Songbei District were aggregated along Songhua River, and most patches in Xiangfang and Daowai Districts were aggregated in the forest botanical garden and Tianhengshan Park. In summary, the forest patches in all administrative districts were aggregated in several separate areas and most areas were treeless.

The forest patches in Harbin were highly fragmented. Small patches covering an area of less than 0.5 ha and patches covering an area of 0.5 to 1 ha accounted for $72.6 \%$ and $19.4 \%$ of all patches, respectively. Large patches covering an area of more than 1 ha accounted for only $8 \%$ of all patches (Fig. 4a). The average patch size was 0.31 ha. Patches with a perimeter of $<500 \mathrm{~m}$ accounted for $80.2 \%$ and patches with a perimeter of more than $1000 \mathrm{~m}$ accounted for only $6.9 \%$ of all patches (Fig. 4b). The average perimeter of the patches was $388 \mathrm{~m}$. Patches with PARA of 
236

237

238

239

240

241

242

243

244

245

246

247

248

249

250

251

252

253

254

255

256

257

258

259

260

more than 0.8 and less than 0.01 accounted for only $7.7 \%$ of all patches. More than $90 \%$ of the patches had PARA of 0.1 to 0.8 , of which $42.6 \%$ had PARA from 0.2 to 0.4 (Fig. $4 \mathrm{c}$ ); the average PARA value was 3251. Most patches (59.62\%) were less than $32 \mathrm{~m}$ away from the nearest neighboring patches, and only less than $1 \%$ of the patches were isolated and more than $512 \mathrm{~m}$ away from other patches. ENN of the remaining patches ranged from $32 \mathrm{~m}$ to $512 \mathrm{~m}$ and they accounted for $39.99 \%$ of all patches (Fig. 4d); the average ENN value was $43 \mathrm{~m}$.

\section{Urban forest carbon: Forest types, administrative districts, and urban-rural gradients}

The total carbon storage in the different forest types was almost equal, ranging from 127 to 133 thousand tons (Table 1). The tree carbon storage density was the highest in EF, and soil carbon storage density was the highest in LF.

The peak value for total carbon storage was detected in Xiangfang District (219 thousand tons), which was 4.9-fold higher than the lowest value in Daoli District. The peak value for tree biomass carbon density was observed in Xiangfang District (104 tons ha $\left.{ }^{-1}\right)$, whereas the peak value for soil carbon density was detected in Daoli District (65 tons ha-1; Table 1).

With respect to urban-rural changes, a general pattern of linear decrease from the urban center to rural regions was found with respect to soil carbon density, whereas no steady changes in tree biomass carbon density were found (Table 1). Carbon storage in the first and second ring roads accounted only for less than $10 \%$ of the total carbon storage in Harbin, and the highest carbon storage was detected in the fourth ring road (262 thousand tons). With respect to different history of urban settlements, the peak value for total carbon storage was in the unsettled region (250 thousand tons), which was 28 -fold higher than the lowest value in the 100-year history region (9 thousand tons). The peak value for tree carbon density was also in the unsettled region, whereas soil carbon density increased along with the history of urban settlements. The peak value for soil carbon density was in the 100-year region (soil carbon density $=0.15 \times$ (year of settlement history) $+50, \mathrm{R}^{2}=0.70, p<0.05$, according to our previous study [Lv et al., 2016]). 
261

262

263

264

265

266

267

268

269

270

271

272

273

274

275

276

277

278

279

280

281

282

283

284

285

286

\section{Landscape metrics: Forest types, administrative districts, and urban-rural gradients}

AF comprised the largest proportion of all forest types, with a TA of about 2 times that of EF. The TAs of LF and RF were almost equal. LF had a low level of fragmentation, with the largest LPI (3.59\%). The patch size (AREA_MN, 1.97 ha) in LF were 5-12-fold and 5-9-fold higher than that in the other forest types, and the lowest PARA_AM (559) and LSI (43.28) in LF were only half of those in the other forest types. EF had the lowest LPI (0.28\%) and the highest ENN_MN (68.89 m); AF and RF had a high level of fragmentation, and they had the lowest AREA_MN (0.22 ha) and higher PARA_AM and LSI than the other forest types (Table 2).

The highest TA of urban forests (1309 ha) and NP (4038) in Xiangfang District were 3.6-fold higher than the lowest TA in Daoli District and 2.8-fold higher than the lowest NP in Daowai District. The largest LPI (13.75\%) and AREA_MN (0.42 ha) in Songbei District were 4.6-fold higher than the lowest LPI in Daowai District and 1.9-fold higher than the lowest AREA_MN in Nangang District. The peak value of ENN_MN (62.54 m) in Daowai District was 1.6-fold higher than that of the lowest value in Nangang District (38.57 m; Table 2).

The TA of the suburb urban regions (third and fourth ring roads; 3388 ha) was 9-fold higher than that of the central urban regions (first and second ring roads; 359 ha). The mean patch size $(<0.16 \mathrm{ha})$ in the central urban area was half of that in the suburb area, and PARA_AM in the central urban area was higher than that in the suburban regions (Table 2). The dispersion of patches (LSI) linearly decreased from the fourth ring road region to the first ring road region (LSI = $33.587 \times$ ring road $+170.35, \mathrm{R}^{2}=0.93, \mathrm{p}=0.034$; Fig. $\left.5 \mathrm{~A}\right)$.

The NP and LSI linearly decreased from the 0 -year history region (rural region) to the 100 year region (urban center) $\left(\mathrm{LSI}=-0.6093 \times\right.$ history $+95.299, \mathrm{R}^{2}=0.7196, p=0.033 ; \mathrm{NP}=-$ $27.158 \times$ history $+3150, \mathrm{R}^{2}=0.6642, p=0.048$; Figs. 5B and $\left.5 \mathrm{C}\right)$. The younger history regions like the 10-year region had the highest TA (1382 ha), NP (3858), and AREA_MN (0.36 ha), and they were 20-fold and 2.6-fold higher than the lowest TA (69 ha) and AREA_MN (0.14 ha) in the 80-year region and 12-fold higher than the lowest NP (311) in the 100-year region (Table 2). 
287

288

289

290

291

292

293

294

295

296

297

298

299

300

301

302

303

304

305

306

307

308

309

310

311

312

313

\section{Associations between forest carbon traits and landscape metrics}

As shown in Table 3 and Figure 6, Pearson's correlation analysis, smoothing analysis, and bivariate normal distribution were used to show the associations between the carbon parameters and landscape metrics. The total tree and soil carbon storage values were positively correlated with TA, NP, AREA_MN, and LSI $(p<0.01)$. Of these 4 indices, peak coefficients were found in TA with tree biomass carbon (0.986) and soil carbon (0.806). The biomass and soil carbon density showed different associations with landscape metrics. When the LF data (outside the bivariate normal distribution ellipse) was excluded, the biomass carbon density was positively correlated with AREA_MN $(p<0.05$, Table 3, Fig. 6), whereas no marked associations were found with the other indices $(p>0.05)$. The soil carbon density was negatively correlated with TA, NP, AREA_MN, and LSI (Table 3, Fig. 6) and positively correlated with LPI ( $p<0.05$, Table 3, Fig. 6). The highest association was found with LPI. No marked relationship was found between soil carbon density and PARA_AM ( $p>0.05$, Table 3, Fig. 6).

The stepwise regression analysis showed that both tree carbon storage and soil carbon storage were mainly associated with TA, whereas other factors such as ENN-MN and AREA-MN were included in the regression model (Table 4). When the standard coefficients were compared, the contribution of TA to carbon storage was 3.5-8.1-fold higher than that of EN-MN or AREA-MN. The stepwise regression analysis showed that the soil carbon storage density was mainly associated with LSI (soil carbon storage density $=-0.158 \times$ LSI $+69.316, \mathrm{r}^{2}=0.51$, Table 4 ), whereas tree carbon storage density was associated with LPI (tree carbon storage density $=-1.848 \times$ LPI + 90.902, $\mathrm{r}^{2}=0.125$, Table 4). These data showed that the carbon density was regulated to a greater extent by patch configuration and aggregation/dispersion than storage (Table 4).

\section{Discussions}

By 2050, there will be 6 billion urban dwellers (Mccarthy et al., 2010). Urbanization, together with climate change, has become the biggest environmental problem worldwide, resulting in increased carbon emissions (Maruotti, 2008; Mccarthy et al., 2010) and urban heat island effects (Zhao et al., 2015; Zhao \& Wentz, 2016). Urbanization also affects landscape fragmentation and 
314

315

316

317

318

319

320

321

322

323

324

325

326

327

328

329

330

331

332

333

334

335

336

337

338

339

340

configuration and diversity of forests (Su et al., 2012) and significantly influences the structure, process, and ecological functions of urban vegetation ecosystems (Yin et al., 2009), including carbon storage function (Zhang et al., 2015; Lv et al., 2016). Urban forest landscape changes along urban-rural gradients are not well-defined, although many ecological functions, such as heat island, biodiversity, tree size, and community features, have been discussed (Larondelle \& Haase, 2013; Lv et al., 2016; Xiao et al., 2016a; Zhang et al., 2017b). Our study has supplemented information on forest landscape metrics and carbon storage in different forest types, administrative districts, and urban-rural gradients (in terms of ring road and settlement history) for better understanding of landscape characteristics under urbanization effects to provide suitable management measures targeted at different regions. The importance of our findings will be discussed below, together with reference comparisons, management suggestions, and future urban forest evaluations.

\section{Landscape fragmentation of urban forests in Harbin City: Quantification and Comparison}

On basis of the overall trend for landscape fragmentation worldwide, fragmentation of the urban forest has been observed to be severe (Liu \& Zhang, 2012; Gong et al., 2013). We used Harbin City as an example and quantified and compared landscape characteristics of urban forests in cities localized and worldwide. The mean patch size at city scale was 0.31 ha in Harbin, which was $29.8 \%$ of the forest patch size in Changchun (Zhang, 2015) and was low when compared with Shenyang (0.22 to 1.04 ha) (Liu et al., 2009). However, patch density (PD) and mean perimeterarea ratio (PARA) in Harbin, which reached up to 3.18 patches ha-1 $^{-1}$ and 3251, respectively, were both more than 3-fold higher than those in Changchun (Zhang, 2015) and high when compared with Shenyang (PD and PARA ranged from 0.99 to 2.87 patches ha ${ }^{-1}$ and 887 to 4109 , respectively) (Liu et al., 2009). These landscape characteristics all indicated a much higher fragmentation level of the urban forests in Harbin than in the localized cities in Northeastern China.

Worldwide urbanization has resulted in broad forest fragmentation. In Puerto Rico, forests became more fragmented between 1991 and 2000; the mean patch size decreased and edge to area ratio increased, the dynamics of forest fragmentation were synchronized with the urban sprawl, 
341 and the peak forest fragmentation shifted towards the rural areas (Gao \& Yu, 2014). In Atlanta, 342 Georgia, forests displayed a fragmentation trend from 1974 to 2005, and this fragmentation trend 343 adversely affected habitat integrity (Miller, 2012). The fragmentation trends caused by 344 urbanization have formed the current spatial structure of urban forests in Atlanta, Georgia (Miller, 345 2012), as in the urban forests in Harbin. The dispersion of patches in terms of LSI and number of 346 patches (NP) decreased along the rural-urban gradients (Fig. 5), showing that forests in the rural 347 regions of Harbin were more dispersed and had more patches than those in the central urban 348 regions. Spatial-temporal gradient analysis of urban green spaces in Jinan also showed that the LSI

of residential green space decreased along the rural-urban gradients, and together with other indices, affected urbanization (Kong \& Nakagoshi, 2006).

Urban forest fragmentation was induced and influenced by many factors, such as urban building density (Liu \& Zhang, 2012); deforestation and reforestation processes during urban sprawl (Gao \& Yu, 2014); socioeconomic factors such as urban structure change, industry-related economic boom, increase in migrant resident population; and increased income of city residents (Gong et al., 2013); economically driven intense anthropogenic activities; and the absence of a sustainable environmental management and conservation strategy (Gounaridis et al., 2014). The fragmented landscape may degrade habitat quality; threaten species richness, abundance, and composition (Iidaand \& Nakashizuka, 1995; Liu et al., 2005); and affect phylogenetic diversity (Matos et al., 2016). This may be a huge risk to forest management in cities such as Harbin. Harbin has experienced an exponential economic growth since the 1980s and population boom since the 1950s (Xiao et al., 2016a), resulting in insufficient greenery services in urban regions. The largely fragmented forest landscapes and uneven distribution in different regions of Harbin City require new efforts for urban forest protection, new plantation afforestation, and sustainable management activities for maximizing urban forest services. 
365

366

367

368

369

370

371

372

373

374

375

376

377

378

379

380

381

382

383

384

385

386

387

388

389

390

391

\section{Landscape metrics responsible for carbon variations and high carbon-oriented managements}

Urban forests can provide various ecosystem services and values to a city and its residents, like the removal of air pollutants (Livesley et al., 2016), alleviation of the urban heat island effect (Zhao et al., 2018), and reduction and offset of carbon emissions (Jim \& Chen, 2009; Nowak et al., 2013). These ecological functions are linked to landscape characteristics based on the common consensus that environmental patterns strongly influence ecological processes (Turner, 1989; Uuemaa et al., 2013). Our findings highlighted that carbon storage function and landscape pattern of urban forests in Harbin are linked and landscape regulation is possible to improve urban vegetation and soil carbon storage. The carbon storage function of urban forests could contribute to the alleviation of climate changes (Nowak et al., 2002) and reduction of the negative effects of fast urbanization (Martin et al., 2015). The increase of carbon storage at individual tree and patch scale is possible through tree health promotion, forest structure adjustment, tree species selection (Nowak et al., 2002), and soil improvement (Jandl et al., 2007). With respect to landscape pattern, it is important to increase carbon storage through landscape regulation, which should be an aspect of promoting forest ecological function in limited urban areas (Ren et al., 2013; Lv et al., 2016).

First, carbon storage in the urban forest trees (and soils) was positively correlated with NP and AREA_MN (Table 3, Fig. 6), which was consistent with the results reported by Wang (2012). In a given urban green space, relatively large forest patches with considerable patch numbers are possible for increasing the urban forest carbon storage in the trees and soils. The much closer relationship between tree carbon storage and TA (Table 3, Fig. 6) indicated that an increase in forest cover is the best way to promote carbon storage function, especially in regions with rather low forest coverage. The increase in total forest coverage could also lower the degree of landscape fragmentation (Liu \& Zhang, 2012) and enhance the cool island effect of urban forests (Ren et al., 2015).

Second, because of limited green spaces in cities, improvement of carbon storage density (tons $\mathrm{ha}^{-1}$ ) through landscape regulations should be more practical and focus on forest construction, 
392 regulation, and functional promotion. For example, we found that the mean patch size and tree

393

394

carbon storage density were positively correlated and increasing the mean patch size may promote tree carbon density in future landscape designs.

Third, LSI and LPI are 2 landscape metrics for carbon-oriented landscape regulation. Our data have shown that LSI and LPI are closely associated with carbon storage at city and plot density levels (Table 3, Fig. 6). LPI is the percentage of the largest patch in the landscape, mainly reflecting configuration. LSI mainly reflects the aggregation/dispersion of patches. Increasing the connectivity and aggregation of patches (decreasing LSI) and improving the promotion of the largest patch in landscape design may favor urban carbon sequestration.

Another parameter for facilitating carbon storage is AREA_MN, which was positively correlated with tree biomass carbon storage after the LF data were excluded (Table 3, Fig. 6). In future urban forest management, afforestation activities targeted at different regions are necessary, especially in regions with low AREA_MN such as Nangang District. Even though tree coverage in Harbin is low, together with other green spaces, green coverage in Harbin could reach up to $36 \%$ of the whole urban landscape (Lv, 2017). Afforestation in existing grassland, wasteland, and illegal construction land that unites small patches into larger and regular-shaped patches would increase the mean patch size and ecological services.

China has devoted a large financial budget for the construction of urban forests, and, by 2020, at least 200 cities will build close-to-nature forests based on the unified design between cities and the countryside to achieve the title of "National Forest City" (Forestry, 2016). On the basis of our findings, Harbin City still has a long way to go to be one of the 200 cities. The urban forest trees in Harbin cover only $7 \%$ of the urban lands, which is much lower than the lower limits for forest city (build-up region green coverage, $40 \%$ at least). In addition, the uneven distribution of urban forests in the different administrative districts and urban-rural gradients may hinder the unified design concept and lead to discrepancies in the ecological functions provided by urban vegetation in different regions. An increase in tree coverage at city scale is necessary to promote the overall ecological benefits of urban forests in Harbin, especially the establishment of a series of country, 
419 city, and community parks. These parks could benefit the local people as long as they open a 420 window or door. Specific designs, such as demolition of illegal structures for tree planting, 421 replanting trees in vacant lots that surround by buildings (Bajsanski et al., 2016; Zhao, 2017; Zhao

422 et al., 2017), and implementation of vertical greening on roofs, walls, and bridges, may increase

423 the connectivity of urban forests and have a positive influence on the fragmented landscape (Gao $424 \&$ Yu, 2014). Previous studies have highlighted that urban greening practices should consider the 425 importance of biodiversity conservation (Xiao et al., 2016a), removal of pollutants (Escobedo \& 426 Nowak, 2009; Mu et al., 2004), urban microclimate regulations (Wang et al., 2018), urban heat 427 island mitigation (Zhang et al., 2017a), and urban soil improvement (Cui \& Mu, 2016; Wang et 428 al., 2017; Zhou et al., 2017). Our findings strongly suggest that urban forest carbon sequestration 429 in both aboveground biomass and belowground soil carbon should be considered for co430 improvement of multiple ecological services.

431

432

433

434

435

436

437

438

439

440

441

442

443

444

445

\section{Implications for the urban forest evaluation and uncertainty}

The total carbon storage of the urban forest within the forth ring road of Harbin City was 521 to 575 thousand tons, of which 302 to 359 thousand tons belongs to tree carbon; this is more than the above 20 thousand tons estimated by Ying et al. (2009). These findings show the large uncertainty in the estimation of urban forest carbon sequestration (Pouyat et al., 2006). Previous studies on the estimation of carbon storage in urban forests always focused on only vegetation biomass carbon and paid less attention to soil carbon (Nowak et al., 2013; Zhang et al., 2015). Urban soils have robust carbon storage capacity, both in the areas covered by green vegetation (Liu et al., 2016) and beneath the impervious surface (Pouyat et al., 2006; Edmondson et al., 2012; Raciti et al., 2012). In the future, belowground soil carbon storage should be analyzed, and both aboveground and belowground carbon inclusion may help in understanding carbon storage capacity of the whole ecosystem.

The scaling up of tree biomass carbon storage in cities was based on several methods without considering landscape metrics, such as model-based estimation including UFORE, CITY green, iTREE, and InVEST (Nowak et al., 2013); remote sensing image-based estimation by using carbon 
446

447

448

449

450

451

452

453

454

455

456

457

458

459

460

461

462

463

464

465

466

467

468

469

470

471

472

storage per pixel and vegetation index, such as NDVI (Myeong et al., 2006); forest inventorybased estimation (Zhang, 2015); and random sampling statistics for plot carbon storage and tree coverage/forest coverage area at different land uses (Liu \& Li, 2012). In this study, forest type, administrative district, ring road, and history-related urban-rural gradients of the urban forests largely differed in carbon density, and approximate scaling-up showed fluctuations in total urban forest carbon storage from 521 to 575 thousand tons (Table 1). The different storage figures were an over-simplified process; it is the product of forest area and corresponding carbon density in tree biomass and soils. Our findings highlight that, besides forest structure data, the comprehensive relationships among landscape metrics, urbanization gradients, and forest types could be included in a more precise evaluation framework. Several aspects should be considered.

First, as shown by the stepwise regression model between carbon storage parameters and landscape metrics, the possible landscape metrics suggested are LSI and LPI for carbon density and TA for total carbon storage estimation in tree biomass and soils (Table 4). With respect to biomass carbon storage, the inclusion of ENN_MN could increase the coefficient $\left(\mathrm{r}^{2}\right)$ from 0.65 (TA only) to 0.71 (TA and ENN_MN), whereas the soil carbon storage model showed that inclusion of AREA_MN increased $\mathrm{r}^{2}$ from 0.97 to 0.99 (Table 4).

Second, urbanization intensity and forest types should be considered in the estimation model. As shown in Table 1, an approximation of total carbon sequestration based on forest types, administrative districts, and urban-rural gradients showed 1.2-fold differences in biomass and 1.1fold variations in soil (Table 1). Urbanization-induced improvement of soil carbon has been reported. In our previous study, we found that the urbanization process (from rural to urban: fourth ring road to first ring road, 0 -year region to 100 -year region) led to the accumulation of SOC in Harbin (Lv et al., 2016), and the same findings were reported in Changchun, China (Zhai et al., 2017). The aggregation and shape complexity of patches decreased (in terms of LSI increased) along with the rural-urban gradients (Fig. 5), and the soil carbon storage density was negatively correlated with LSI (Fig. 6). This may possibly provide an explanation for SOC accumulation from the viewpoint of landscape. Small and shape-complex patches dispersed in the rural landscapes 
473 formed larger LSI and more easily exchanged substance and energy with the external environment 474 than the big and regular-shaped patches aggregated in the urban landscapes, including 475 carbonaceous compounds, and may contribute to steady and higher carbon storage in central urban 476 forests. In general, urbanization intensity differences and forest type differences are strongly 477 associated with landscape variations in the forest.

478 Third, background urbanization conditions have been proved to be strongly associated with 479 various ecological functions of urban forests, and their contributions to forest carbon sequestration 480 need to be included. Building geography, e.g., street orientation (Sanusi et al., 2016); street canyon 481 features, e.g., building height and distance to measured trees (Coutts et al., 2016; Morakinyo et al., 482 2017; Rahman et al., 2017); land use configurations (building, street, green space, and water); and 483 impervious surface percentage (Zhang et al., 2017b) have been proven to affect thermal regulation 484 by trees, biodiversity conservation, and forest structural traits. In this paper, no such data are 485 available, and future studies are required.

486 In the future, a well-matched, large dataset including all the above-mentioned parameters 487 (independent of each other) would facilitate the derivation of a feasible method for scaling-up of 488 city-level carbon storage density or total storage estimation. For example, landscape metrics in a 489 fixed-sized area (e.g., $2 \mathrm{~km}$ around the field plot) (Zhang et al., 2017b), together with data on tree 490 size and forest community features, soil carbon density and background road features, impervious 491 surface features, as well as urban-rural gradients and forest types, will favor proper model 492 construction for a proper scaling-up method via a statistical method such as the stepwise regression 493 method used in this study (Table 4). This study has provided hints on the possible parameters for 494 future consideration.

\section{Conclusions}

The landscape of urban forests in Harbin was highly fragmented when compared with other local cities, and the fragmentation was different in different forest types, administrative districts, ring road- and urban history-related urban-rural gradients. The fragmentation of the landscape was 
500

501

502

503

504

505

506

507

508

509

510

511

512

513

514

515

516

517

518

519

520

521

522

523

524

525

526

527

528 strongly associated with carbon storage functions in trees and soils. LSI increased along with the urban-rural gradients, and its positive relationship with SOC indicates that LSI contributes to the underlying mechanism of urbanization-induced carbon accumulation in highly urbanized regions. The relationships between carbon storage and landscape metrics manifested possible ways to improve the urban forest carbon storage, such as improvement of the whole urban carbon storage by increasing the afforested area. An increase in the largest patch percentage and patch aggregation could increase the soil carbon storage per hectare. This study would help to promote carbonoriented management practices for urban vegetation and exact evaluation of urban forest carbon sequestration by including landscape metrics and urbanization intensities.

\section{Acknowledgements:}

Thanks are due to Manli Ren and Zhongxue Pei for their help during field survey, and Professor Kaishan Song for his help while image processing.

\section{References}

Bao S. 2000. Soil Agro-chemistrical Analysis. China Agriculture Press: Beijing, China.

Bajsanski I, Stojakovic V, Jovanovic M. 2016. Effect of tree location on mitigating parking lot insolation. Computers, Environment and Urban Systems, 56, 59-67. DOI: 10.1016/j.compenvurbsys.2015.11.006

Chang J. 2015. The study on the investigation of soil in urban green space and effects for the improving in Harbin. Master of Science, Thesis, Northeast Forestry University.

Chen TB, Zheng YM, Lei M, Huang ZC, Wu HT, Chen H, Fan KK, Yu K, Wu X and Tian QZ. 2005. Assessment of heavy metal pollution in surface soils of urban parks in Beijing, China. Chemosphere 60: 542-551. DOI: 10.1016/j.chemosphere.2004.12.072

Edmondson JL, Davies ZG, McHugh N, Gaston KJ and Leake JR. 2012. Organic carbon hidden in urban ecosystems. Scientific Reports 2. DOI: 10.1038/srep00963.

Escobedo, F, Varela S, Zhao M, Wagner JE. and Zipperer W. 2010. Analyzing the efficacy of subtropical urban forests in offsetting carbon emissions from cities. Environmental Science \& Policy 13: 362-372. DOI: 10.1016/j.envsci.2010.03.009 
529 Escobedo FJ. and Nowak DJ. 2009. Spatial heterogeneity and air pollution removal by an urban 530 forest. Landscape and Urban Planning 90: 102-110. DOI: 10.1016/j.landurbplan.2008.10.021

531 Forestry C. 2016. The guidance of the construction of Forest City releaseed by the State Forestry 532 Administration. Available at http:/www.forestry.gov.cn/main/4818/content-907127.html, 533 (accessed 12 Sepetmber 2016)

534 Gao Q and Yu M. 2014. Discerning Fragmentation Dynamics of Tropical Forest and Wetland 535 during Reforestation, Urban Sprawl, and Policy Shifts. Plos One 9. DOI: 536 10.1371/journal.pone.0113140

537 Gong C, Yu S, Joesting H, and Chen J. 2013. Determining socioeconomic drivers of urban forest 538 fragmentation with historical remote sensing images. Landscape and Urban Planning 117:57-65. 539 DOI: 10.1016/j.landurbplan.2013.04.009

540 Gounaridis D, Zaimes GN, and Koukoulas S. 2014. Quantifying spatio-temporal patterns of forest 541 fragmentation in Hymettus Mountain, Greece. Computers, Environment and Urban Systems 542 46:35-44. DOI: 10.1016/j.compenvurbsys.2014.04.003

543 He X, Liu C, Chen W, Guan Z, and Zhao G. 2004. Discussion on urban forest classification. 544 Chinese Journal of Ecology 23:175-178+185. DOI: 10.13292/j.1000-4890.2004.0175

545 Huang D, Su Z, Zhang R, and Koh LP. 2010. Degree of urbanization influences the persistence of 546 Dorytomus weevils (Coleoptera: Curculionoidae) in Beijing, China. Landscape and Urban 547 Planning 96:163-171. DOI: 10.1016/j.landurbplan.2010.03.004

548 Iida S, and Nakashizuka T. 1995. Forest fragmentation and its effect on species diversity in sub549 urban coppice forests in Japan. Forest Ecology and Management 73:197-210. DOI: 10.1016/0378550 1127(94)03484-E

551 Jandl R, Lindner M, Vesterdal L, Bauwens B, Baritz R, Hagedorn F, Johnson DW, Minkkinen K, 552 and Byrne KA. 2007. How strongly can forest management influence soil carbon sequestration? 553 Geoderma 137:253-268. DOI: 10.1016/j.geoderma.2006.09.003

554 Jim CY, and Chen WY. 2009. Ecosystem services and valuation of urban forests in China. Cities 555 26:187-194. DOI: 10.1016/j.cities.2009.03.003

556 Jo HK. 2002. Impacts of urban greenspace on offsetting carbon emissions for middle Korea. $J$ 557 Environ Manage 64:115-126. DOI: 10.1006/jema.2001.0491

558 Kong F, and Nakagoshi N. 2006. Spatial-temporal gradient analysis of urban green spaces in Jinan, 559 China. Landscape and Urban Planning 78:147-164. DOI: 10.1016/j.landurbplan.2005.07.006

560 Larondelle N, and Haase D. 2013. Urban ecosystem services assessment along a rural-urban 561 gradient: a cross-analysis of European cities. Ecological Indicators 29:179-190. DOI: $56210.1016 /$ j.ecolind.2012.12.022 
563 Li, X, Zhang, C, Li, W, Kuzovkina, YA, and Weiner, D 2015. Who lives in greener 564 neighborhoods? the distribution of street greenery and its association with residents' 565 socioeconomic conditions in hartford, connecticut, USA. Urban Forestry \& Urban 566 Greening, 14(4), 751-759. DOI: $\underline{\text { 10.1016/j.ufug.2015.07.006 }}$

567

568

569

Liu C, Li J, Li X, He X, and Chen W. 2009. Selection of landscaoe pattern metrics for urban forest based on simulated landscapes. Journal of Applied Ecology 20:1125-1131.

Liu C, and Li X. 2012. Carbon storage and sequestration by urban forests in Shenyang, China. Urban Forestry \& Urban Greening 11:121-128. DOI: 10.1016/j.ufug.2011.03.002

Liu C, Li X, and Guo R. 2007. Forest landscape pattern analysis in different districts of Shenyang. Journal of Liaoning Forestry Science \&Technology:4-6.

Liu C, and Zhang M. 2012. Landscape defragmentation trends of urban forests under different building densities. Journal of Northwest Forestry University 27:266-271.

Liu J, Xiao W, Jiang Z, Feng X, and Li X. 2005. A study on the influence of landscape fragmentation on biodiversity. Forest Research 18:222-226.

Liu XL, Li T, Zhang SR, Jia YX, Li Y, and Xu XX. 2016. The role of land use, construction and road on terrestrial carbon stocks in a newly urbanized area of western Chengdu, China. Landscape and Urban Planning 147:88-95. DOI: 10.1016/j.landurbplan.2015.12.001

Livesley SJ, McPherson GM, and Calfapietra C. 2016. The Urban Forest and Ecosystem Services: Impacts on Urban Water, Heat, and Pollution Cycles at the Tree, Street, and City Scale. Journal of Environment Quality, 45(1), 119. DOI: 10.2134/jeq2015.11.0567

Lu J, Shen G, Wang Q, Ren M, Pei Z, Wei C, and Wang W. 2016. Effect of urban tree species on soil physicochemical properties in Harbin, Northeastern China, and afforestation implications. Bulletin of Botanical Research 36:549-555. DOI: 10.7525/j.issn.1673-5102.2016.04.010

Lv HL. 2017. Spatial and temporal variations of urban vegetation and soil carbon storage: a case study in Harbin. D. Phil. Thesis, University of Chinese Academy of Sciences.

Lv H, Wang W, He X, Xiao L, Zhou W, and Zhang B. 2016. Quantifying tree and soil carbon stocks in a temperate urban forest in Northeast China. Forests 7:200-218. DOI: 10.3390/f7090200

Maruotti, A. 2008. "The impact of urbanization on $\mathrm{CO}_{2}$ emissions: Evidence from developing countries." Ecological Economics 70(7): 1344-1353. DOI:10.1016/j.ecolecon.2011.02.009

Martin de Jong, Simon Joss, Daan Schraven, Changjie Zhan, and Margot Weijnen. 2015. Sustainable-smart-resilient-low carbon-eco-knowledge cities; making sense of a multitude of concepts promoting sustainable urbanization. Journal of Cleaner production 109: 25-38. DOI: 10.1016/j.jclepro.2015.02.004 
596 Matos FAR, Magnago LFS, Gastauer M, Carreiras J, Simonelli M, Meira - Neto JAA, and

597 Edwards DP. 2016. Effects of landscape configuration and composition on phylogenetic diversity 598 of trees in a highly fragmented tropical forest. Journal of Ecology. 105: 265-276. DOI: $599 \quad 10.1111 / 1365-2745.12661$

600 Mccarthy M P, Best M J, Betts R A. 2010. Climate change in cities due to global warming and 601 urban effects. Geophysical Research Letters 37(9): 232-256. DOI: 10.1029/2010GL042845

602 Miller MD. 2012. The impacts of Atlanta's urban sprawl on forest cover and fragmentation. 603

604

605

606

607

608

609

610

611

612

613

614

615

616

617

618

619

620

621

622

623

624

625

626

627

\section{Applied Geography 34:171-179. DOI: 10.1016/j.apgeog.2011.11.010}

Nowak DJ, Greenfield EJ, Hoehn RE, and Lapoint E. 2013. Carbon storage and sequestration by trees in urban and community areas of the United States. Environ Pollut 178:229-236. DOI: 10.1016/j.envpol.2013.03.019

Nowak DJ, Stevens JC, Sisinni SM, and Luley CJ. 2002. Effects of urban tree management and species selection on atmospheric carbon dioxide. Journal of Arboriculture 28:113-122.

Pouyat RV, Yesilonis ID, and Nowak DJ. 2006. Carbon storage by urban soils in the United States. Journal of Environmental Quality 35:1566-1575. DOI:10.2134/jeq2005.0215

Raciti SM, Hutyra LR, and Finzi AC. 2012. Depleted soil carbon and nitrogen pools beneath impervious surfaces. Environ Pollut 164:248-251. DOI: 10.1016/j.envpol.2012.01.046

Ren Y, Wei X, Wang D, Luo Y, Song X, Wang Y, Yang Y, and Hua L. 2013. Linking landscape patterns with ecological functions: A case study examining the interaction between landscape heterogeneity and carbon stock of urban forests in Xiamen, China. Forest Ecology and Management 293:122-131. DOI: 10.1016/j.foreco.2012.12.043

Ren Z, Zheng H, He X, Zhang D, and Yu X. 2015. Estimation of the Relationship Between Urban Vegetation Configuration and Land Surface Temperature with Remote Sensing. Journal of the Indian Society of Remote Sensing 43:89-100. DOI: 10.1007/s12524-014-0373-9

Setala H, Viippola V, Rantalainen AL, Pennanen A, and Yli-Pelkonen V. 2013. Does urban vegetation mitigate air pollution in northern conditions? Environ Pollut 183:104-112. DOI: 10.1016/j.envpol.2012.11.010

Su S, Xiao R, Jiang Z, and Zhang Y. 2012. Characterizing landscape pattern and ecosystem service value changes for urbanization impacts at an eco-regional scale. Applied Geography 34:295-305. DOI: 10.1016/j.apgeog.2011.12.001

Turner MG. 1989. Landscape ecology: the effect of pattern on process. Annual review of ecology and systematic $20: 171-197$. 
628 Uuemaa E, Mander Ü, and Marja R. 2013. Trends in the use of landscape spatial metrics as

629 landscape indicators: a review. Ecological Indicators 28:100-106. DOI:

630 10.1016/j.ecolind.2012.07.018

631 Wang W, Qiu L, Zu Y, Su D, An J, Wang H, Zheng G, Sun W, and Sun X. 2011. Changes in soil 632 organic carbon, nitrogen, $\mathrm{pH}$ and bulk density with the development of larch (Larix gmelinii) 633 plantations in China. Global Change Biology 17: 2657-2676. DOI: 10.1111/j.1365634 2486.2011.02447.x

635 Wang W, Zu Y, Wang H, Matsuura Y, Sasa K, and Koike T. 2005. Plant biomass and productivity 636 of Larix gmelinii forest ecosystems in Northeast China: intra-and inter-species comparison. Euasia 637 Journal of Forest Reseach 8: 21-41.

638 Wentz E A, Zhao Q. 2015. Assessing validation methods for building identification and extraction. 639 In Urban Remote Sensing Event (JURSE). IEEE. 1-4. DOI: 10.1109/JURSE.2015.7120453

640 Xiao L, Wang W, He X, Lv H, Wei C, Zhang B, and Zhou W. 2016a. Urban-rural and temporal 641 differences of woody plants and bird species in Harbin city, northeastern China. Urban Forestry 642 \& Urban Greening 20:20-31. DOI: 10.1016/j.ufug.2016.07.013

643 Xiao L, Wang W, Zhang D, He X, Wei C, Lv H, Zhou W, and Zhang B. 2016b. Urban forest tree 644 species composition and arrangement reasonability in Harbin, northeast China. Chinese Journal 645 of Ecology 35:2074-2081. DOI: 10.13292 /j.1000-4890.201608.027

646 Yi Q, Shuai Y, Wang L, Xue L, and Xu P. 2006. Trends and development process of Harbin 647 population. Journal of Nanjing college for population programme management 22:5-8.

648 Yin K, Zhao Q, Cui S, Lin T, and Shi L. 2009. Progresses in urban forest and landscape pattern. 649 Acta Ecologica Sinica v.29:389-398.

650 Ying T, Li M, and Fan W. 2009. Estimation pf carbon sotrage of urban forests in Harbin. Journal 651 of Northeast Forestry University 37:33-35.

652 Zhai C, Wang W, He X, Zhou W, Xiao L, Zhang B. 2017. Urbanization drives SOC accumulation, 653 Its temperature stability and turnover in forests, Northeastern China. Forests, 8: 130-148. DOI: $65410.3390 / \mathrm{f} 8040130$

655 Zhang D. 2015. Spatial-temporal changes of urban forest structure and carbon storage under rapid 656 urbanization: A case study in Changchun. D. Phil. Thesis, University of Chinese Academy of 657 Sciences.

658 Zhang D, Zheng H, Ren Z, Zhai C, Shen G, Mao Z, Wang P, and He X. 2015. Effects of forest 659 type and urbanization on carbon storage of urban forests in Changchun, Northeast China. Chinese 660 Geographical Science 25:147-158. DOI: 10.1007/s11769-015-0743-4

661 Zhang X, Chen L, Ji J, Wang J, Wang Y, Guo W, and Lan B. 2011. Climate change and its effect 662 in Harbin from 1881 to 2010. Journal of Meteorology and Environment 27:13-20. 
663 Zhao M, Kong ZH, Escobedo FJ, and Gao J. 2010. Impacts of urban forests on offsetting carbon

664 emissions from industrial energy use in Hangzhou, China. J Environ Manage 91:807-813. DOI:

665 10.1016/j.jenvman.2009.10.010

666 Zhao, Q. 2017. Evaluating the Effectiveness of Tree Locations and Arrangements for Improving 667 Urban Thermal Environment (PhD Thesis). Arizona State University.

668 Zhao Q, Myint SW, Wentz EA, and Fan C. 2015. Rooftop surface temperature analysis in an urban 669 residential environment. Remote Sensing 7(9): 12135-12159. DOI: 10.3390/rs70912135

670 Zhao Q and Wentz EA. 2016. A MODIS/ASTER airborne simulator (MASTER) imagery for 671 urban heat island research. Data 1(1). DOI: 10.3390/data1010007

672 Zhao Q, Wentz EA, Murray AT. 2017. Tree shade coverage optimization in an urban residential 673 environment. Building and Environment 115, 269 - 280. DOI: 10.1016/j.buildenv.2017.01.036

674 Zhao Q, Yang J, Wang ZH, and Wentz E. 2018. Assessing the Cooling Benefits of Tree Shade by 675 an Outdoor Urban Physical Scale Model at Tempe, AZ. Urban Science, 2(1), 4. DOI: 676 10.3390/urbansci2010004

677 Zhong Z, Wang W, Zhang W, and Wang Q. 2016. Compositional variation of glomalin-related 678 soil protein in different forest stands and farmland. Journal of Beijing Forestry University 38:107679 115. DOI: 10.13332/j.1000-1522.20150399 
Figure 1

Location of the study area showing Harbin City in northeastern China, and the distribution of sampling plots at different forest type, administrative districts and urbanrural gradients of different ring road and history of urban settlements in Harbin.
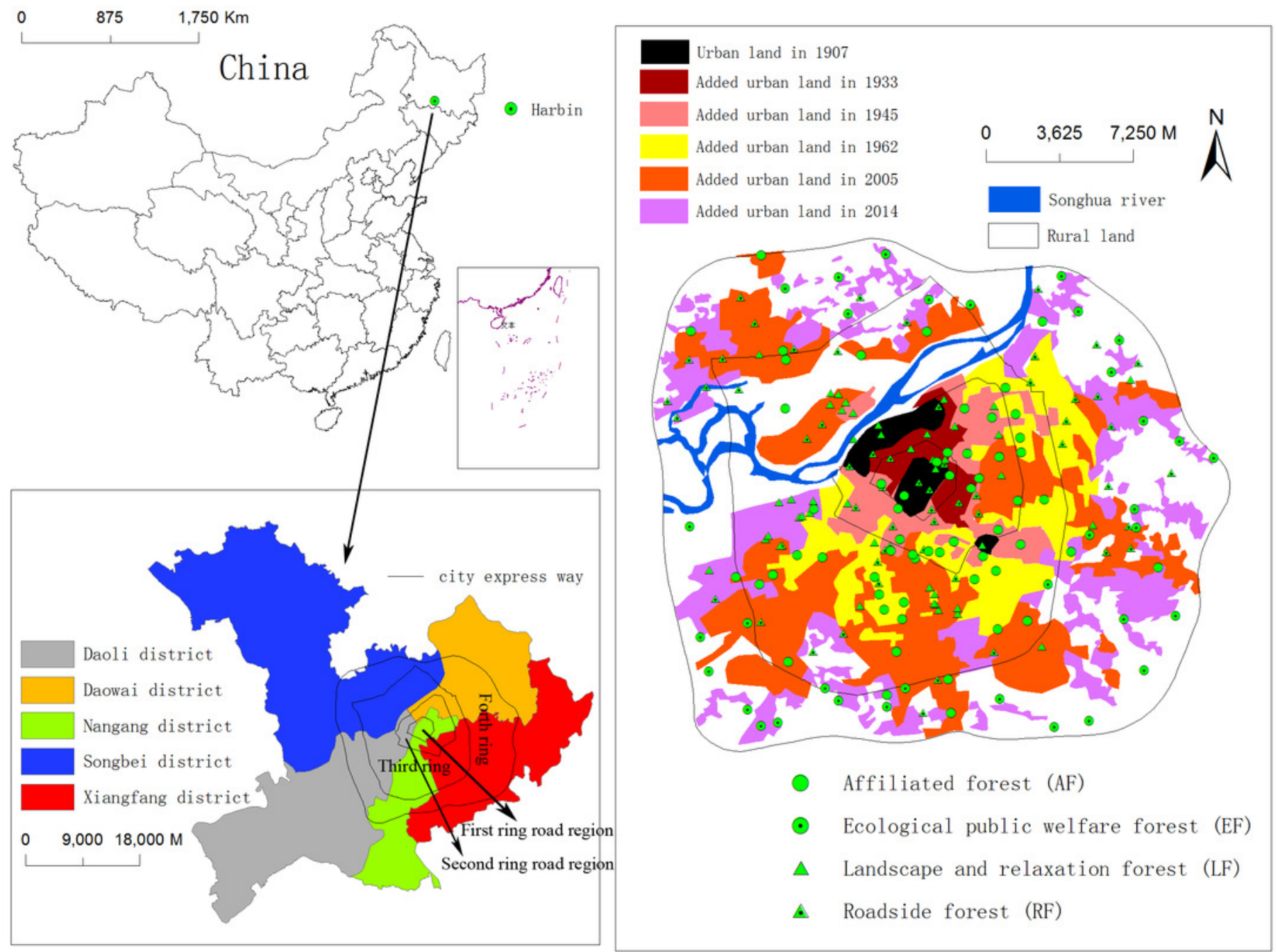
Figure 2

Precision validation for tree cover data of urban forests in Harbin City using Google earth images with a resolution of $0.59 \mathrm{~m}$

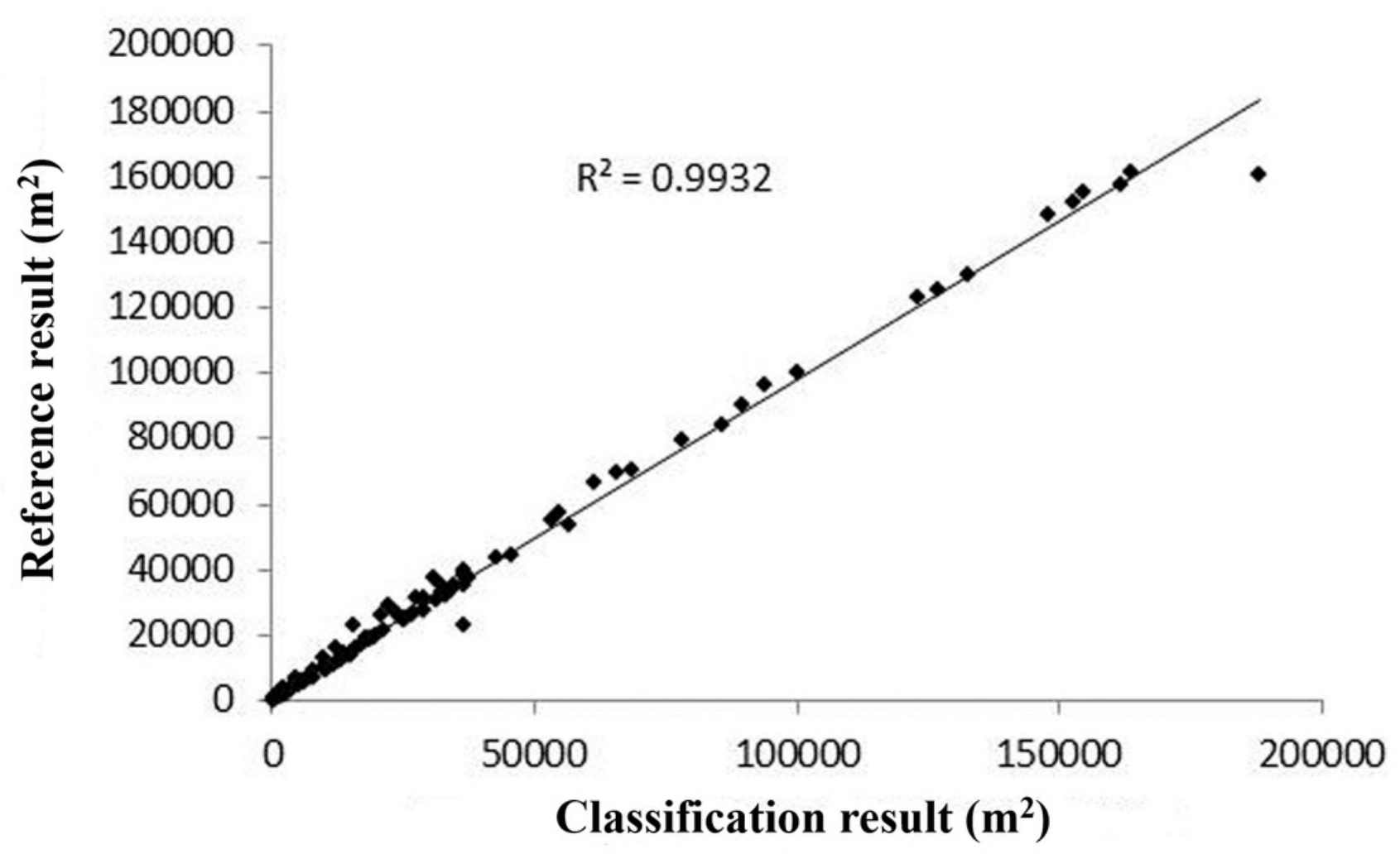


Figure 3

Spatial distribution of urban forests in Harbin City derived from GF1 images (2 m resolution) 


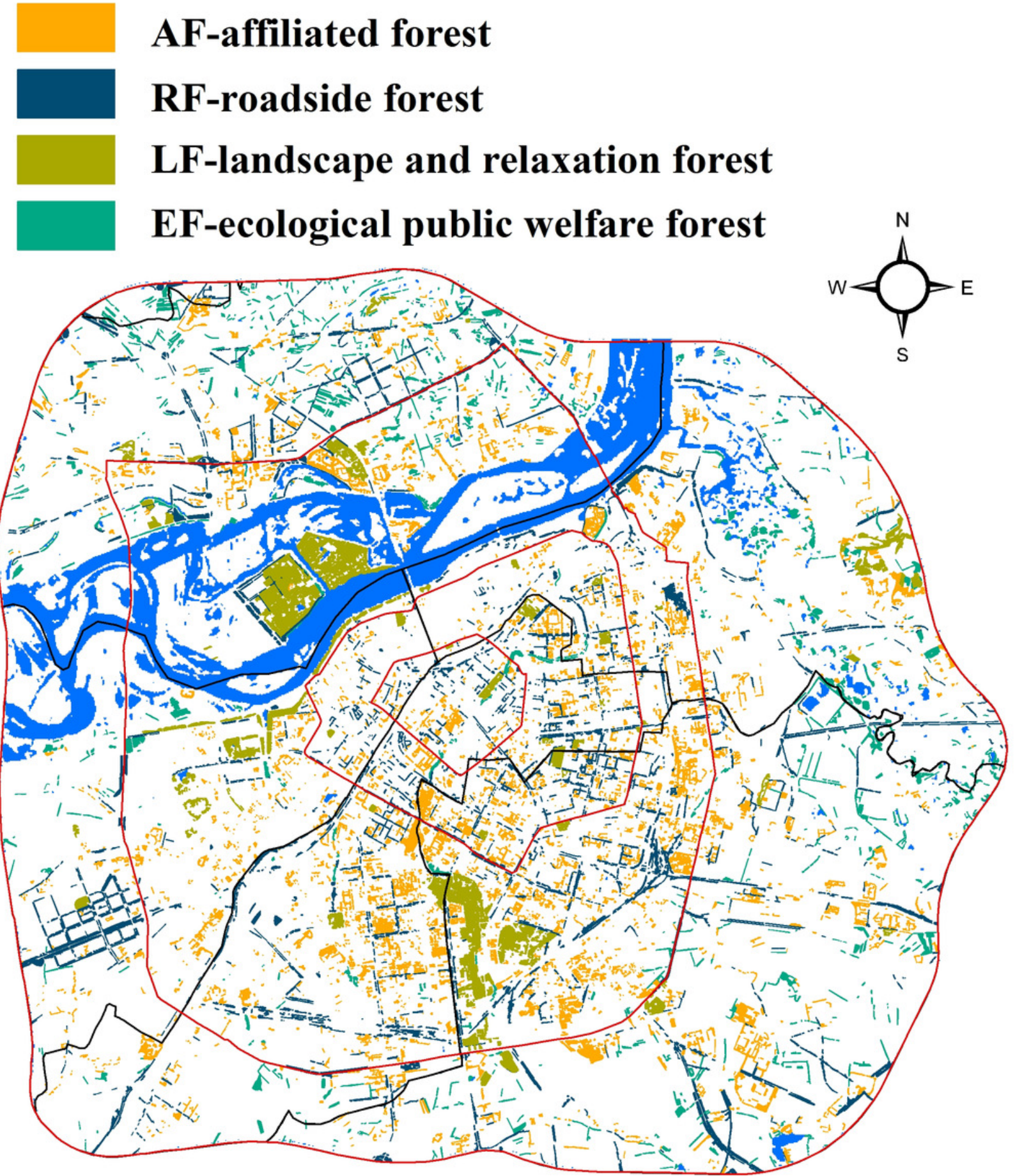

Songhua river and water region

Ring road

Administrative district boundry 


\section{Figure 4}

Frequency distribution of urban forests patch area (a), perimeter (b), perimeter-area ratio (c), and Euclidean nearest neighbor distance (d) in Harbin City

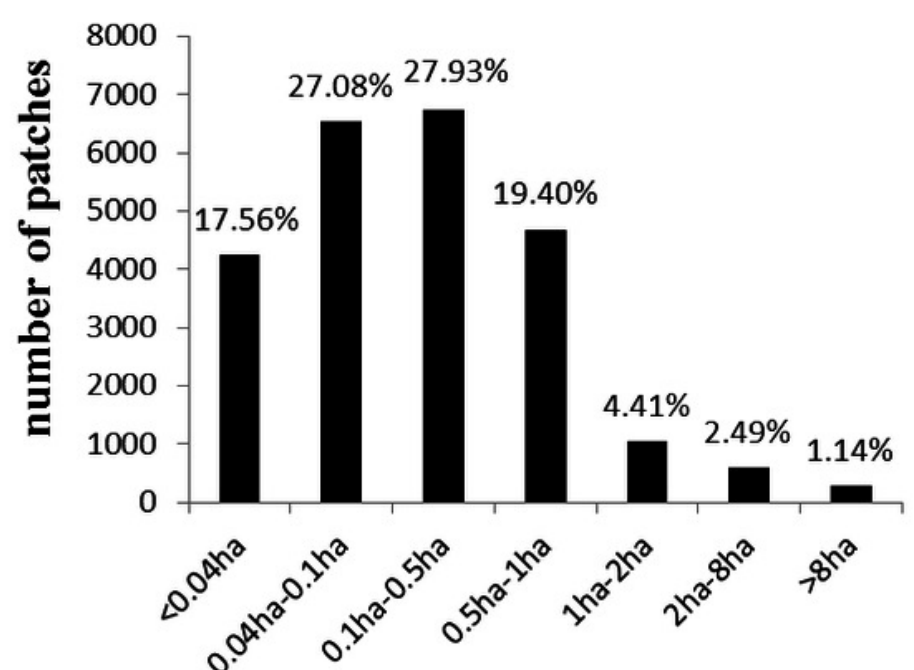

a patch area

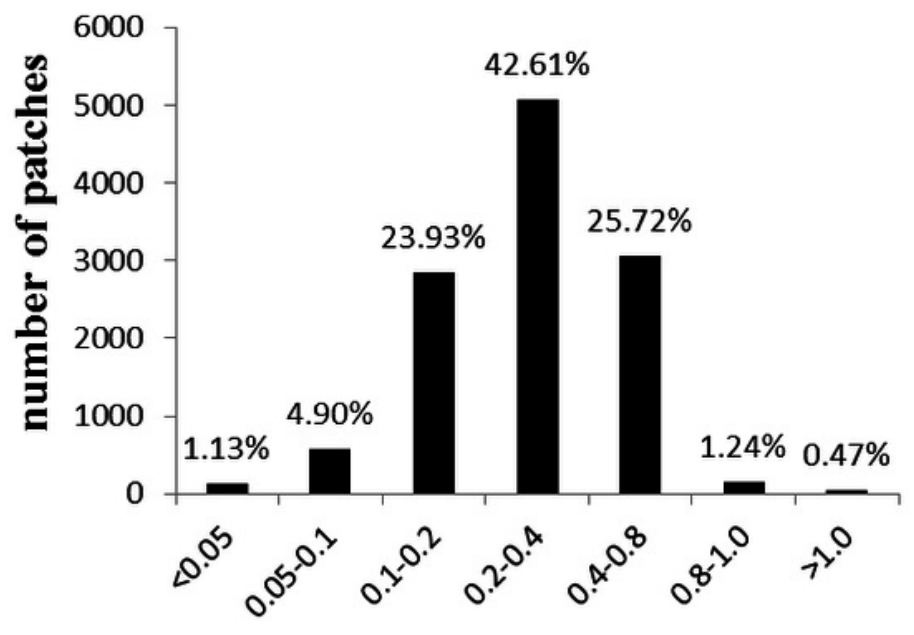

c PARA (perimeter-area ratio)

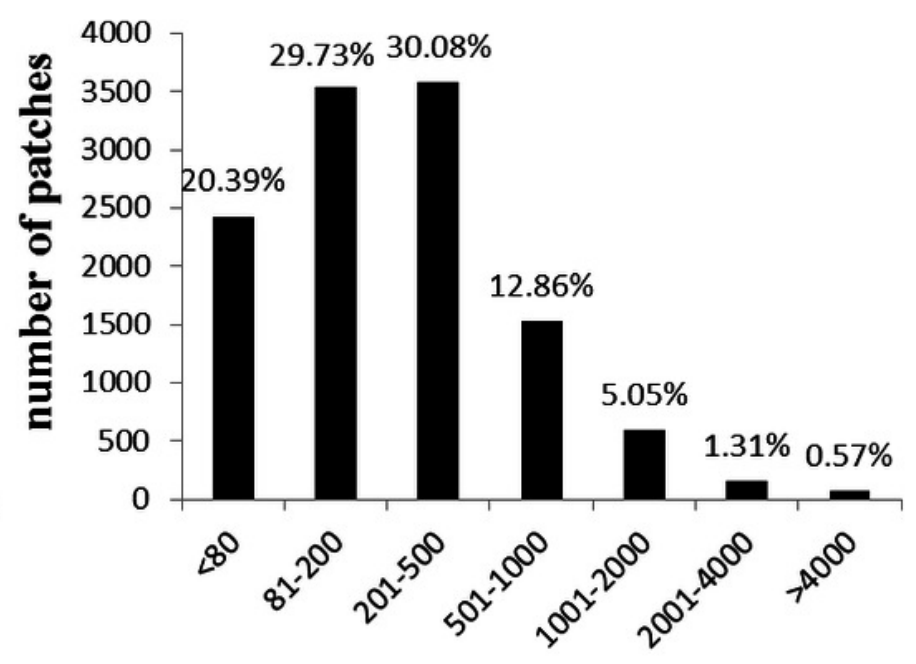

b patch perimeter $(\mathbf{m})$

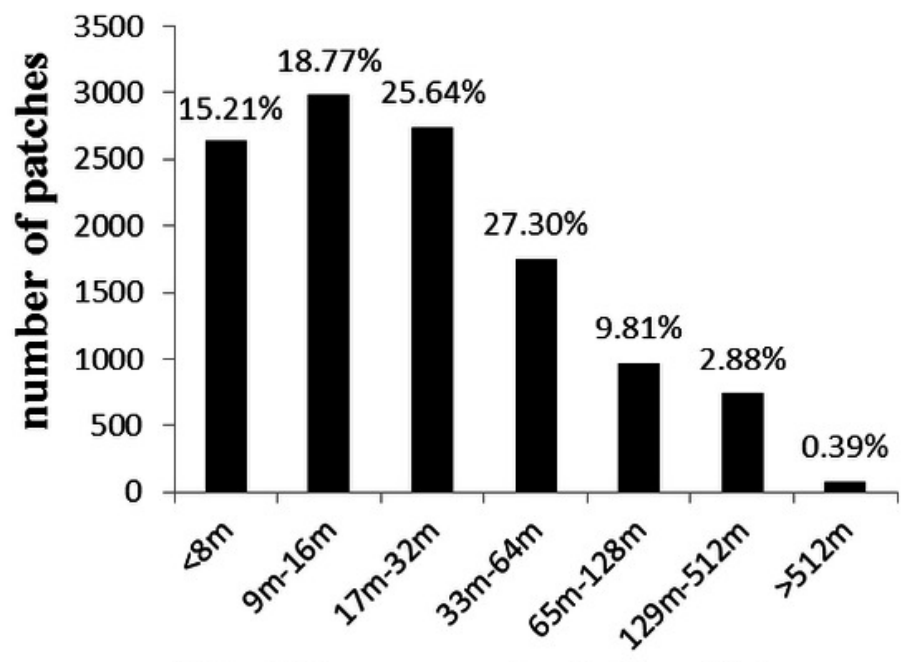

d Euclidean nearest-neighbor distance 


\section{Figure 5}

Changes of landscape shape index (LSI) and number of patches (NP) of urban forests along urban-rural gradients (ring roads or history of settlements) in Harbin City.
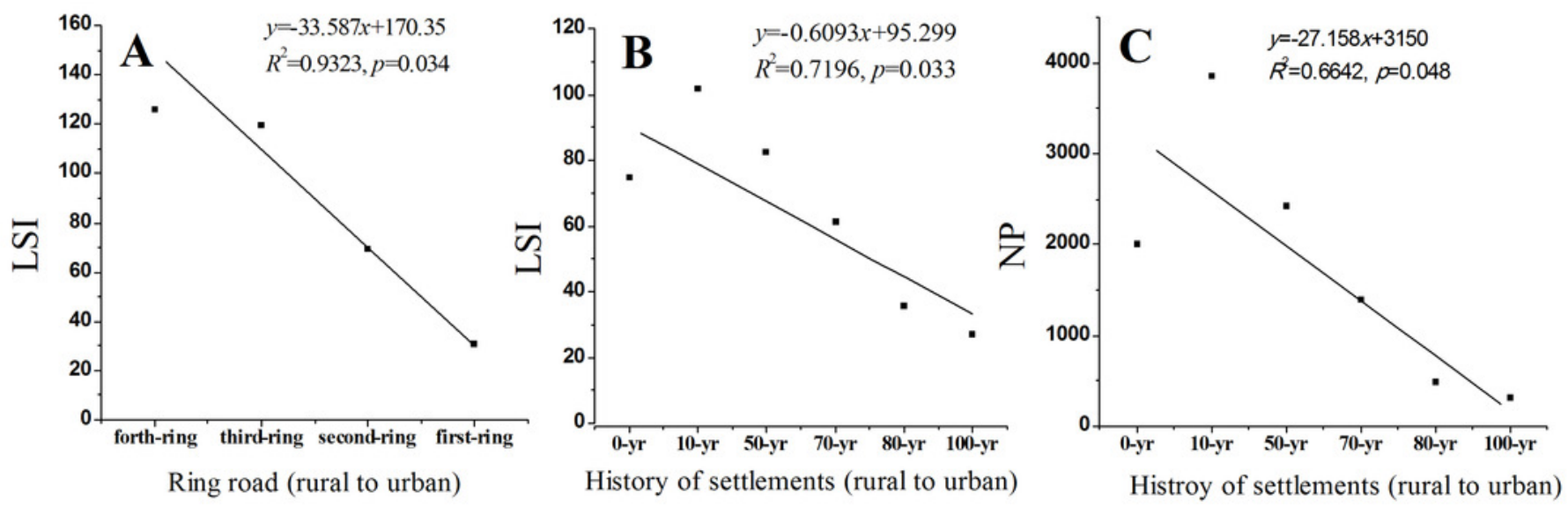


\section{Figure 6}

Associations between different landscape metrics and soil-C density, biomass- $\mathrm{C}$ density, soil-C storage as well as biomass- $C$ storage.

Note: The line in the figure is the smoothed line of the raw data. The ellipse in the figure is the bivariate normal distribution of the raw data. Triangle is the LF data, which is much larger than other in Area-MN, and without LF, area-MN had good linear relations with various carbon parameters. Different color of the labels in the figures showed the data originated from administrative districts, forest types, urban history and ringroad development regions.

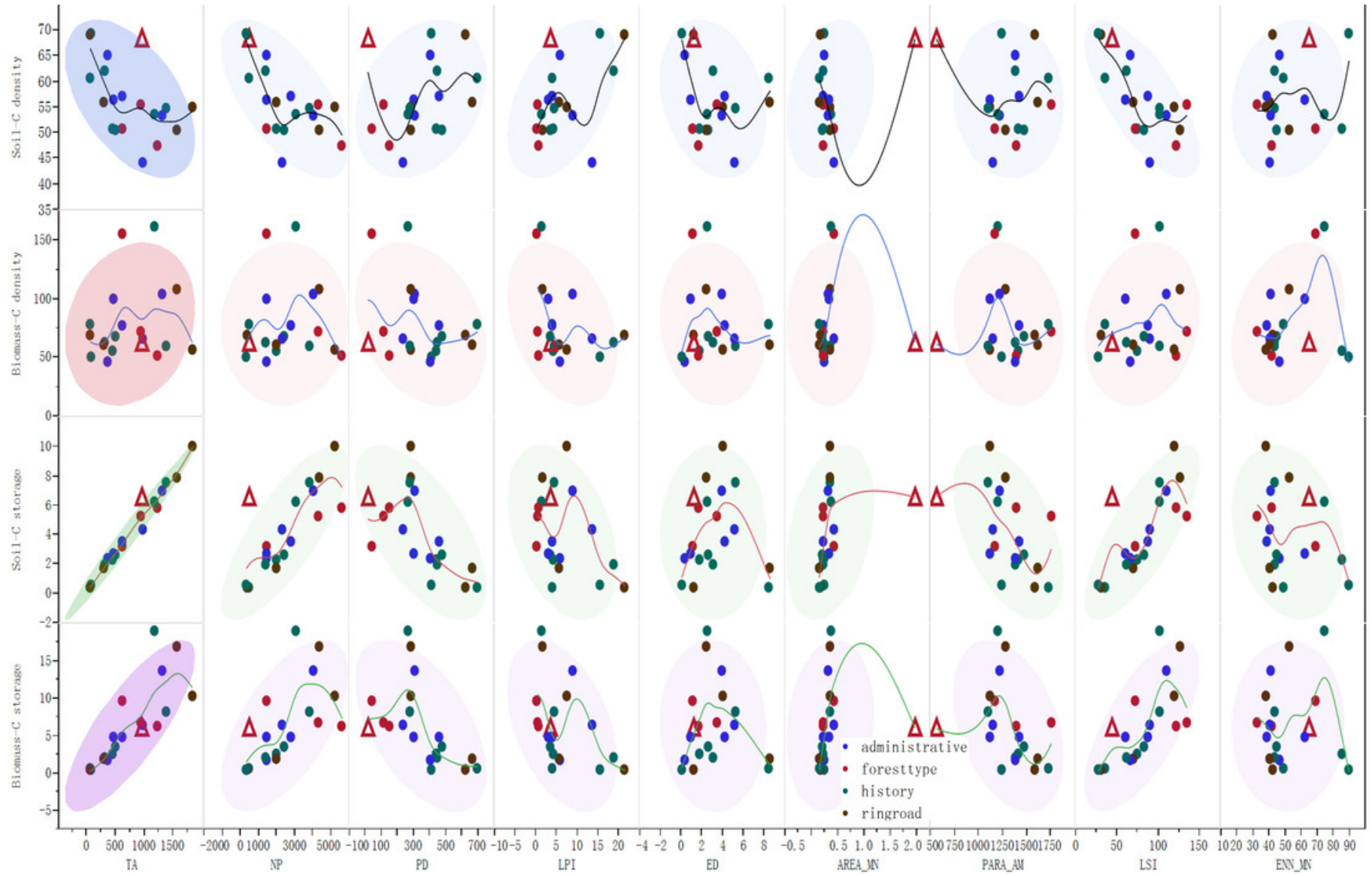




\section{Table $\mathbf{1}$ (on next page)}

Trees and soils carbon storage for different forest types, administrative districts, urbanrural gradients (ring-roads and history of urban settlements) in Harbin City

Note: AF, affiliated forest; RF, roadside forest; LF, landscape and relaxation forest; $E F$, ecological public welfare forest. 100-yr, urban area constructed before 1906; 80-yr, urban area constructed between 1933 and 1907; 70-yr, urban area constructed between 1945 and 1934; 50-yr, urban area constructed between 1962 and 1946; 10-yr, urban area constructed between 2005 and 1963; 0-yr, urban area constructed during 2006 and 2014; unsettlement, rural land. The numbers in brackets are standard errors. 
1 Table 1 Trees and soils carbon storage for different forest types, administrative districts, urban2 rural gradients (ring-roads and history of urban settlements) in Harbin City

\begin{tabular}{|c|c|c|c|c|c|c|c|c|}
\hline \multirow[t]{2}{*}{$\begin{array}{l}\text { Urban forests } \\
\text { classification }\end{array}$} & & \multirow{2}{*}{$\begin{array}{l}\text { No. } \\
\text { of } \\
\text { plots }\end{array}$} & \multirow{2}{*}{$\begin{array}{l}\text { Area of } \\
\text { the } \\
\text { region } \\
\mathrm{km}^{2}\end{array}$} & \multicolumn{3}{|c|}{$\begin{array}{l}\text { carbon storage } \\
\text { (thousand tons) }\end{array}$} & \multicolumn{2}{|c|}{$\begin{array}{l}\text { C storage density } \\
\left(\text { tons } \mathrm{ha}^{-1}\right)\end{array}$} \\
\hline & & & & Tree & Soil & Total & Tree biomass & Soil \\
\hline \multicolumn{9}{|c|}{ Different forest types and regions } \\
\hline \multirow[t]{4}{*}{ Forest types } & $\mathrm{AF}$ & 58 & $12^{\mathrm{a}}$ & 68.9 & 63.7 & 132.6 & $51.4(6.4)$ & $47.5(3.4)$ \\
\hline & RF & 42 & $9^{\mathrm{a}}$ & 72.6 & 56.2 & 128.8 & $71.6(10.6)$ & $55.4(3.1)$ \\
\hline & $\mathrm{LF}$ & 62 & $10^{\mathrm{a}}$ & 60.9 & 66.3 & 127.2 & $62.9(8.6)$ & $68.5(5.5)$ \\
\hline & $\mathrm{EF}$ & 36 & $6^{\mathrm{a}}$ & 100.0 & 32.7 & 132.7 & $155.0(12.2)$ & $50.7(3.6)$ \\
\hline \multirow{5}{*}{$\begin{array}{l}\text { Administrative } \\
\text { districts }\end{array}$} & Daoli & 34 & 90 & 18.5 & 26.1 & 44.6 & $46.2(8.3)$ & $65.2(6.8)$ \\
\hline & Daowai & 30 & 96 & 52.7 & 29.8 & 82.5 & $100.0(1.9)$ & $56.5(4.3)$ \\
\hline & Nangang & 49 & 92 & 51.5 & 38.0 & 89.5 & $77.5(8.3)$ & $57.2(3.9)$ \\
\hline & Songbei & 34 & 143 & 64.8 & 43.3 & 108.1 & $66.1(8.4)$ & $44.1(4.1)$ \\
\hline & Xiangfang & 50 & 167 & 144.8 & 74.2 & 219.0 & $104.0(13.3)$ & $53.3(3.4)$ \\
\hline \multicolumn{9}{|c|}{ Urban-rural gradients } \\
\hline \multirow[t]{4}{*}{ Ring roads } & First ring & 16 & 11 & 4.8 & 4.8 & 9.6 & $68.8(13.8)$ & $69.1(4.9)$ \\
\hline & $\begin{array}{l}\text { Second } \\
\text { ring }\end{array}$ & 32 & 48 & 22.7 & 21.0 & 43.7 & $60.8(8.1)$ & $56.1(5.7)$ \\
\hline & Third ring & 77 & 205 & 105.1 & 102.8 & 207.9 & $56.1(5.8)$ & $54.9(3.4)$ \\
\hline & Fourth ring & 74 & 328 & 178.1 & 83.4 & 261.5 & $108.1(1.2)$ & $50.6(3.0)$ \\
\hline \multirow{7}{*}{$\begin{array}{l}\text { History of } \\
\text { urban } \\
\text { settlements }\end{array}$} & $100-y r$ & 7 & 12 & 3.8 & 5.2 & 9.0 & $50.3(16.5)$ & $69.4(6.3)$ \\
\hline & $80-y r$ & 10 & 13 & 5.4 & 4.2 & 9.6 & $78.7(15.8)$ & $60.6(9.0)$ \\
\hline & $70-y r$ & 28 & 32 & 19.7 & 19.5 & 39.2 & $62.6(9.2)$ & $62.0(5.1)$ \\
\hline & $50-y r$ & 27 & 62 & 34.8 & 25.7 & 60.5 & $68.4(14.9)$ & $50.6(5.2)$ \\
\hline & $10-y r$ & 44 & 138 & 82.4 & 75.8 & 158.2 & $59.6(9.8)$ & $54.8(3.3)$ \\
\hline & $0-y r$ & 51 & 92 & 25.0 & 23.0 & 48.0 & $55.2(8.2)$ & $50.7(5.0)$ \\
\hline & unsettled & 32 & 242 & 188.0 & 62.2 & 250.2 & $161.8(13.4)$ & $53.5(3.9)$ \\
\hline \multicolumn{2}{|l|}{ Sum } & 199 & & $\begin{array}{l}302- \\
359\end{array}$ & $\begin{array}{l}211- \\
219\end{array}$ & $\begin{array}{l}521- \\
575\end{array}$ & & \\
\hline
\end{tabular}

3 Note: AF, affiliated forest; RF, roadside forest; LF, landscape and relaxation forest; EF, 4 ecological public welfare forest. 100-yr, urban area constructed before 1906; 80-yr, urban area 5 constructed between 1933 and 1907; 70-yr, urban area constructed between 1945 and 1934; 50$6 \mathrm{yr}$, urban area constructed between 1962 and 1946; 10-yr, urban area constructed between 2005 7 and 1963; 0-yr, urban area constructed during 2006 and 2014; unsettlement, rural land. The 8 numbers in brackets are standard errors. a in superscript is tree coverage area. 


\section{Table 2 (on next page)}

Landscape metrics of different types, administrative districts, and urban-rural gradients (ring roads and history of settlements) of urban forests in Harbin City

Note: AF, affiliated forest; $R F$, roadside forest; $L F$, landscape and relaxation forest; $E F$, ecological public welfare forest. 100-yr, urban area constructed before 1906; 80-yr, urban area constructed between 1933 and 1907; 70-yr, urban area constructed between 1945 and 1934; 50-yr, urban area constructed between 1962 and 1946; 10-yr, urban area constructed between 2005 and 1963; 0-yr, urban area constructed during 2006 and 2014; unsettlement, rural land. TA, total area; NP, number of patches; LPI, largest patch index; AREA_MN, mean patch area; PARA_AM, Area mean Perimeter-Area Ratio Distribution; LSI, Landscape Shape Index; ENN_MN, Mean Euclidean Nearest Neighbor Distance Distribution. 
1 Table 2 Landscape metrics of different types, administrative districts, and urban-rural gradients (ring roads and history of settlements) of urban forests in Harbin City

\begin{tabular}{|c|c|c|c|c|c|c|c|c|}
\hline \multicolumn{2}{|c|}{$\begin{array}{l}\text { Urban forests } \\
\text { classification }\end{array}$} & $\begin{array}{l}\text { TA } \\
\text { (ha) }\end{array}$ & NP & $\begin{array}{l}\text { LPI } \\
(\%)\end{array}$ & $\begin{array}{c}\text { AREA } \\
\text {-MN } \\
\text { (ha) }\end{array}$ & $\begin{array}{c}\text { PARA } \\
\text { AM }\end{array}$ & LSI & $\begin{array}{c}\mathrm{ENN} \\
\mathrm{MN} \\
(\mathrm{m})\end{array}$ \\
\hline \multicolumn{9}{|c|}{ Different forest types and regions } \\
\hline \multirow{2}{*}{$\begin{array}{l}\text { Forest } \\
\text { types }\end{array}$} & $\mathrm{AF}$ & 1226 & 5631 & 0.69 & 0.22 & 1394 & 121.99 & 41.63 \\
\hline & RF & 942 & 4327 & 0.41 & 0.22 & 1752 & 134.38 & 32.42 \\
\hline \multirow{7}{*}{$\begin{array}{l}\text { Administra } \\
\text { tive } \\
\text { districts }\end{array}$} & $\mathrm{LF}$ & 959 & 488 & 3.59 & 1.97 & 559 & 43.28 & 64.57 \\
\hline & EF & 620 & 1463 & 0.28 & 0.42 & 1165 & 72.47 & 68.89 \\
\hline & Daoli & 364 & 1477 & 5.78 & 0.25 & 1385 & 65.98 & 46.70 \\
\hline & Daowai & 474 & 1435 & 2.96 & 0.33 & 1116 & 60.70 & 62.54 \\
\hline & Nangang & 614 & 2803 & 3.99 & 0.22 & 1420 & 87.67 & 38.57 \\
\hline & Songbei & 981 & 2315 & 13.75 & 0.42 & 1151 & 89.74 & 40.59 \\
\hline & Xiangfang & 1309 & 4038 & 8.89 & 0.32 & 1216 & 109.62 & 41.15 \\
\hline \multicolumn{9}{|c|}{ Urban-rural gradients } \\
\hline \multirow{4}{*}{$\begin{array}{l}\text { Ring road } \\
\text { regions }\end{array}$} & First ring & 60 & 372 & 21.55 & 0.16 & 1582 & 30.55 & 42.12 \\
\hline & $\begin{array}{l}\text { Second } \\
\text { ring }\end{array}$ & 299 & 2001 & 5.65 & 0.15 & 1620 & 69.65 & 40.19 \\
\hline & Third ring & 1827 & 5224 & 7.39 & 0.35 & 1121 & 119.38 & 38.20 \\
\hline & Fourth ring & 1561 & 4392 & 1.65 & 0.36 & 1278 & 125.93 & 52.78 \\
\hline \multirow{7}{*}{$\begin{array}{l}\text { History of } \\
\text { urban } \\
\text { settlements }\end{array}$} & $100-y r$ & 75 & 311 & 15.44 & 0.24 & 1242 & 26.93 & 89.64 \\
\hline & $80-y r$ & 69 & 482 & 3.99 & 0.14 & 1725 & 35.67 & 49.00 \\
\hline & $70-y r$ & 315 & 1404 & 18.86 & 0.22 & 1385 & 61.27 & 43.60 \\
\hline & $50-y r$ & 508 & 2418 & 3.47 & 0.21 & 1468 & 82.57 & 44.93 \\
\hline & $10-y r$ & 1382 & 3858 & 4.36 & 0.36 & 1100 & 101.71 & 43.31 \\
\hline & $0-y r$ & 453 & 2008 & 4.12 & 0.23 & 1407 & 74.77 & 85.30 \\
\hline & unsettled & 1169 & 3067 & 1.44 & 0.38 & 1196 & 102.02 & 74.16 \\
\hline
\end{tabular}

3 Note: AF, affiliated forest; RF, roadside forest; LF, landscape and relaxation forest; EF, 4 ecological public welfare forest. 100-yr, urban area constructed before 1906; 80-yr, urban area 5 constructed between 1933 and 1907; 70-yr, urban area constructed between 1945 and 1934; 50$6 \mathrm{yr}$, urban area constructed between 1962 and 1946; 10-yr, urban area constructed between 2005 7 and 1963; 0-yr, urban area constructed during 2006 and 2014; unsettlement, rural land. TA, total 8 area; NP, number of patches; LPI, largest patch index; AREA_MN, mean patch area; 9 PARA_AM, Area mean Perimeter-Area Ratio Distribution; LSI, Landscape Shape Index; 10 ENN_MN, Mean Euclidean Nearest Neighbor Distance Distribution. 


\section{Table 3 (on next page)}

Pearson correlation analysis between landscape metrics and biomass and soil carbon storage (thousand tons) of urban forests in Harbin City. Number of sample size $=20$.

Note: * represent 0.05 significant level, and ** represent 0.01 significant level. TA, total area; NP, number of patches; LPI, largest patch index; AREA_MN, mean patch area; PARA_AM, Area mean Perimeter-Area Ratio Distribution; LSI, Landscape Shape Index; ENN_MN, Mean Euclidean Nearest Neighbor Distance Distribution. 
1 Table 3 Pearson correlation analysis between landscape metrics and biomass and soil carbon storage (thousand tons) of urban forests in Harbin City. Number of sample size $=20$.

\begin{tabular}{|c|c|c|c|c|c|c|c|c|}
\hline Items & $\begin{array}{l}\text { Pearson } \\
\text { correlation }\end{array}$ & TA (ha) & NP & $\begin{array}{l}\text { LPI } \\
(\%)\end{array}$ & $\begin{array}{l}\text { AREA_ } \\
\text { MN (ha) }\end{array}$ & $\begin{array}{c}\text { PARA } \\
\text { AM }\end{array}$ & LSI & $\begin{array}{l}\text { ENN_M } \\
\mathrm{N}(\mathrm{m})\end{array}$ \\
\hline \multirow{2}{*}{$\begin{array}{l}\text { Storage } \\
\text { (ton) }\end{array}$} & Tree C & $0.986^{* *}$ & $0.782^{* *}$ & -0.388 & $0.608^{* *}$ & $-0.505^{*}$ & $0.769^{* *}$ & -0.238 \\
\hline & Soil C & $0.806^{* *}$ & $0.609^{* *}$ & -0.422 & $0.716^{* *}$ & -0.370 & $0.687^{* *}$ & 0.026 \\
\hline \multirow{2}{*}{$\begin{array}{l}\text { Density } \\
\text { (ton } \mathrm{ha}^{-1} \text { ) }\end{array}$} & Tree C & 0.196 & 0.043 & -0.353 & $0.533^{*}$ & -0.154 & 0.180 & 0.276 \\
\hline & Soil C & $-0.518^{*}$ & $-0.644^{* *}$ & $0.466^{*}$ & $-0.503^{*}$ & -0.060 & $-0.713^{* *}$ & 0.182 \\
\hline
\end{tabular}

3 Note: * represent 0.05 significant level, and ** represent 0.01 significant level. TA, total area; 4 NP, number of patches; LPI, largest patch index; AREA_MN, mean patch area; PARA_AM, 5 Area mean Perimeter-Area Ratio Distribution; LSI, Landscape Shape Index; ENN_MN, Mean

6 Euclidean Nearest Neighbor Distance Distribution. 
Table 4 (on next page)

Stepwise regression between forest carbon parameters and landscape metrics. Stepwise Criteria: Probability-of-F-to-enter $<=0.200$, Probability-of-F-to-remove $>=$ 0.300 . 
1 Table 4. Stepwise regression between forest carbon parameters and landscape metrics. Stepwise

2 Criteria: Probability-of-F-to-enter $<=0.200$, Probability-of-F-to-remove $>=0.300$.

\begin{tabular}{|c|c|c|c|c|c|c|c|}
\hline \multirow[t]{2}{*}{ Response variables } & \multirow[t]{2}{*}{ Parameters } & \multicolumn{2}{|c|}{$\begin{array}{l}\text { Unstandardized } \\
\text { Coeff. }\end{array}$} & \multirow{2}{*}{$\begin{array}{l}\text { Standardized } \\
\text { Coeff. } \\
\text { Beta }\end{array}$} & \multirow[t]{2}{*}{$\begin{array}{l}\text { t- } \\
\text { value }\end{array}$} & \multirow[t]{2}{*}{ Sig. } & \multirow[t]{2}{*}{$\mathrm{R}^{2}$} \\
\hline & & $\mathrm{B}$ & $\begin{array}{l}\text { Std. } \\
\text { Error }\end{array}$ & & & & \\
\hline \multicolumn{8}{|l|}{ Density } \\
\hline \multirow[t]{2}{*}{ SOC density } & (Constant) & 69.316 & 3.183 & & 21.780 & 0.000 & 0.508 \\
\hline & LSI & -0.158 & 0.037 & -0.713 & -4.312 & 0.000 & \\
\hline \multirow[t]{2}{*}{ Biomass-C density } & (Constant) & 90.092 & 10.161 & & 8.866 & 0.000 & 0.125 \\
\hline & LPI & -1.848 & 1.153 & -0.353 & -1.603 & 0.126 & \\
\hline \multicolumn{8}{|l|}{ Storage } \\
\hline \multirow[t]{3}{*}{ Biomass-C storage } & (Constant) & -4.702 & 2.847 & & -1.651 & 0.117 & 0.708 \\
\hline & TA & 0.009 & 0.001 & 0.870 & 6.414 & 0.000 & \\
\hline & ENN_MN & 0.081 & 0.044 & 0.249 & 1.838 & 0.084 & \\
\hline \multirow[t]{3}{*}{ SOC storage } & (Constant) & -0.051 & 0.150 & & -0.342 & 0.736 & 0.986 \\
\hline & $\mathrm{TA}$ & 0.005 & 0.000 & 0.959 & 32.050 & 0.000 & \\
\hline & AREA_MN & 0.849 & 0.215 & 0.118 & 3.956 & 0.001 & \\
\hline
\end{tabular}

3 